\title{
Estimation of Contrail Frequency and Radiative Effects over the Taiwan Area
}

\author{
Jen-Ping Chen ${ }^{1, \star}$, Wei-Hung Lin ${ }^{1}$, and Ruei-Fong Lin ${ }^{2}$
}

(Manuscript received 20 March 2000, in final form 22 May 2000)

\begin{abstract}
The radiative effect of aircraft contrails over the Taiwan area was studied using a climatological analysis of contrail occurrence frequency and numerical simulations of contrail formation. Although the most suitable altitude for the formation of contrails is $14 \sim 16 \mathrm{~km}$, most contrails appear at heights between 10 and $12 \mathrm{~km}$ due to the altitude constraint on flying. Winter and spring are the most favorable seasons for contrail formation, whereas summer is the most unfavorable. After formation, $86 \%$ of the contrails will dissipate while the remainder will grow and persist. For more detailed analysis, we classify contrails into 12 types according to the climatology of contrail-forming conditions. The microphysical and radiative properties of each type of contrails were simulated using a two-dimensional cirrus model. From the simulation we obtained a time-averaged top-of-atmosphere longwave radiative forcing of about $1.1 \mathrm{~W} \mathrm{~m} \mathrm{~m}^{-2}$ and $16 \mathrm{~W} \mathrm{~m}$ directly under a dissipating and persistent contrail, respectively; whereas the shortwave radiative forcing, with the sun directly overhead, were $-\mathbf{- 2 . 6} \mathrm{W} \mathrm{m}^{-2}$ and -40 $\mathrm{W} \mathbf{m}^{-2}$, respectively.

By considering the effect of upper-wind advection on the regional distribution, a climatological analysis of the upper-wind distribution was performed. The time evolutions of the radiative effects were then converted into spatial distributions along all flight corridors over the Taiwan area. On any particular day, the average longwave radiative forcing on a regional scale is about $0.08 \mathrm{~W} \mathrm{~m} \mathrm{~m}^{-2}$ when the atmosphere is suitable for forming dissipating contrails. The average longwave radiative forcing for persistent contrails is about $0.68 \mathrm{~W} \mathrm{~m}$. The shortwave forcing is typically about 2.4 times greater in manitude than the longwave forcing, thus the net effect is a cooling of surface temperatures. Taking into account the occurrence frequency of different contrail types and diurnal flight frequency
\end{abstract}

${ }^{1}$ Department of Atmospheric Sciences, National Taiwan University, Taipei, Taiwan, ROC

${ }^{2}$ Currently at the Goddard Earth Sciences and Technology Center, University of Maryland, Baltimore County, USA

${ }^{*}$ Corresponding author address: Prof. Jen-Ping Chen, Dept. of Atmospheric Sciences, National Taiwan University, \#1, section 4, Roosevelt Road, Taipei, Taiwan, ROC; E-mail: jpchen @water.as.ntu.edu.tw 


\title{
variations, the annual mean effect is a cooling of $-0.006 \mathrm{~W} \mathrm{~m}^{-2}$ over the entire region, but may reach about $-0.03 \mathrm{~W} \mathrm{~m}^{-2}$ near the flight corridors.
}

\author{
(Key words: Contrail, Radiative forcing, Taiwan Flight Information Region)
}

\section{INTRODUCTION}

During the past few decades the growing concern about the anthropogenic influences on our environment has brought attention to the possible role of aircraft activities. It was suggested that the combustion products from aircraft engine, including soot and sulfate particles, water vapor and various trace gases, as well as their secondary derivatives, have the potential to influence the climate (Grassl 1991; Sassen 1997; IPCC 1999). Although the absolute emissions by aircraft are only a few percent of the surface emissions, their effects are nevertheless potentially important because the pollutants are directly injected into the upper troposphere and lower stratosphere where the radiation balance is particularly sensitive to the addition of trace chemicals (Schumann 1994). Besides the direct injection of greenhouse gases and their precursors into the high altitudes, air transport activities have another unique effect that may directly influence climate - cirrus-like condensation trails (or contrails) which are produced almost instantaneously when the exhausts of high-flying modern aircraft mix with sufficiently cold ambient air. Contrails may increase the frequency of cirrus cloud occurrence and total cloud amounts. Their microphysical properties are similar to natural cirrus clouds, which not only reflect sunlight but also absorb and re-emit longwave radiation from and back to the Earth's surface (Liou 1986). Therefore contrails have long been considered as possible regional climate modifiers (Murcray 1970; Kuhn 1970; Changnon 1981).

Many studies have shown an increase in both cirrus frequency and cirrus cloud cover since the beginning of the jet aircraft era (i.e., the early 1960s). In a climatological analysis for the period of 1901 to 1977 over the mid-western United States, Changnon (1981) found that more cloud cover, less sunshine, and reduced surface temperature extremes for the period since 1960 compared to the earlier period. Seaver and Lee (1987) also found a decrease in cloudless day over large regions of the United States since 1936. Observations in Germany indicate that the frequency of high clouds during sunny hours increased from $45 \%$ in 1954 to $70 \%$ in 1995 (Vandersee 1997; Winkler et al. 1997), whereas the global radiation during sunshine hours decreased by about $10 \%$ over the same period (Rebetez and Beniston 1998). A similar increase in high cloud frequency is also observed for cloudy conditions (Liepert et al. 1994; Liepert 1997). Boucher (1999) analyzed the ground-based observation data over North America for the period 1982-1991 and found a decadal increase of 5.6\% for the entire region, and $13.3 \%$ over the heavy air traffic areas. He also found a global trend of $1.7 \%$ per decade over land and $6.2 \%$ per decade over the oceans. Using data from the International Satellite Cloud Climatology Project, Minnis et al. (2000) found similar global rends for the same period.

In an attempt to connect the increase of cirrus cloud with aircraft activities, Liou et al. (1990) analyzed the annual high cloud cover over Salt Lake City from 1948 to 1982 . They found that the mean high-cloud amounts are $11.8 \%$ and $16.9 \%$ for the period before and after 
1964, respectively, with a sharp transition in the mid-1960s. By correlating the consumption rate of jet aircraft fuel, they suggested that such a sharp increase in high-cloud cover could be linked to the rapid increase of domestic air traffic. Frankel et al. (1997) and Boucher (1998, 1999) also reached similar conclusions. The changes in cirrus cloud cover or occurrence frequency should not be directly attributed to contrails, however, because of the influence of natural variability and other anthropogenic effects. More direct evidence is available from cloud photographs.

Figure la shows a photo taken in Taipei during June 1998, showing parallel line-shaped contrails embedded in natural cirrus clouds. Figure $1 \mathrm{~b}$ is a similar situation photographed by a SPOT satellite over the northern Taiwan area. Such views can be commonly seen in the skies of this area. Note that the simple line-shaped contrails in Fig. 1a were photographed in the early afternoon. The contrails produced later that day exhibit significant horizontal spreading, a phenomenon that has been widely recognized. The fish-eye photographs of contrails taken in Salt Lake City also exhibit such spreading $28 \%$ of the time (Sassen 1997). The pictures in Fig. 2 were taken on 1999/7/3 in Albany, New York, at a location near the heavy air traffic region in the Northeastern United States. The spreading of these persistent contrails is quite obvious in Fig. 2a. As the spreading continues, the entire sky appears to be covered with cirrus clouds in just a couple of hours (Fig. 2b). Sassen (1997) mentioned that contrails tend to be seen in advance of naturally occurring cirrus clouds. By observing the development of contrails and cirrus clouds shown in Fig. 2, we noticed that a majority of the cirrus clouds conceivably were derived from contrails instead of occurring naturally.

Several long-term evidences also suggest that contrail formation may significantly increase cirrus cloud cover. Sassen (1997) analyzed fish-eye photographs taken in Salt Lake City and found identifiable contrails in $20 \%$ of the samples. These contrails correlated well
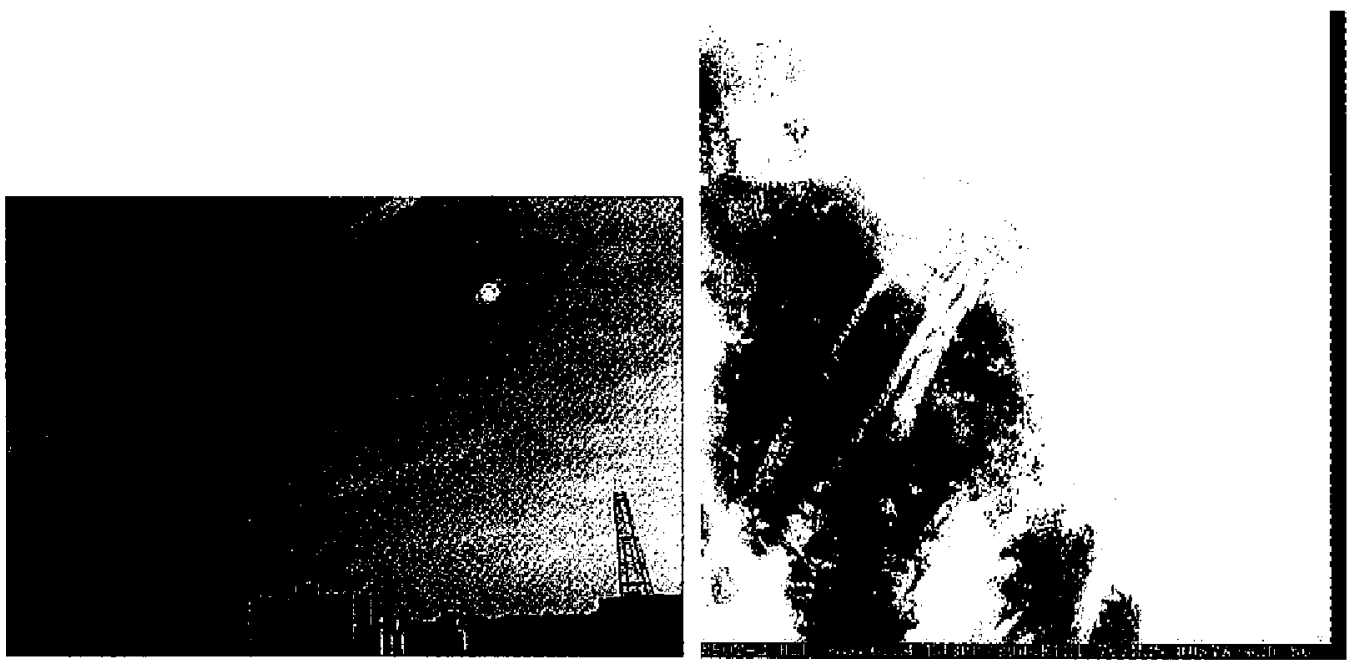

Fig. 1. (a) A photograph of contrails taken in Taipei, Taiwan; (b) Contrail occurrence over the northern Taiwan area revealed by a SPOT satellite. 

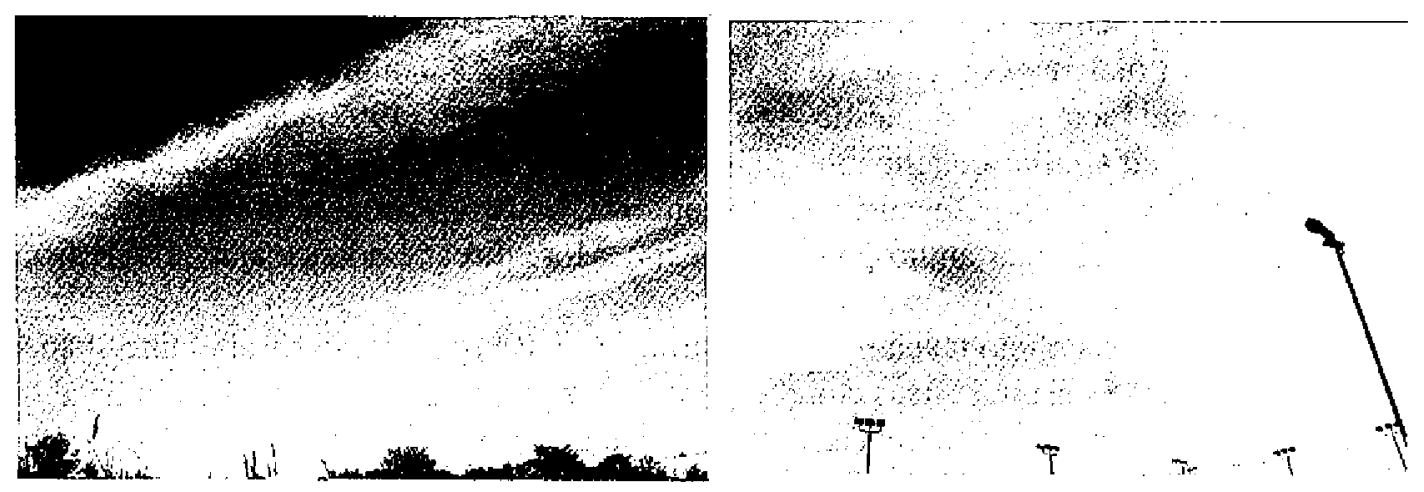

Fig. 2. Contrail photographs taken in Albany New York on July 3, 1999. (a) Around 3 O'clock in the afternoon, several persistent contrails appeared in parallel with significant horizontal spreading; (b) $1 \sim 2$ hours later the cirrus cloud pattern became chaotic with contrails of different ages embedded in broad cirrus coverage.

with the overall high-cloud data records. To obtain a global perspective, Minnis et al. (2000) analyzed 1984-1990 satellite data to obtain cirrus cloud occurrence frequency for gross air traffic areas (contrail areas) and no air traffic area (non-contrail area). They found that the trend for cirrus occurrence in contrail areas was $4.7 \%$ per decade over land and $5.9 \%$ per decade over the ocean. The decadal increase in non-contrail areas was $1.2 \%$ over land and 4 . $3 \%$ over the ocean. Overall, the increase in cirrus cloud occurrence was significantly greater (1.9\% higher per decade globally) in contrail areas with respect to non-contrail areas, indicating the importance of contrail formation. Further evidence is derived from an analysis of AVHRR infrared images for the periods 1979-1981 and 1989-1992 by Bakan et al. (1994), who found a mean contrail cover of $0.5 \%$ over Europe and the Northeast Atlantic. Gierens et al. (1999) estimated that the contrail cloud cover was about $0.1 \%$ globally, with a local maximum of $5 \%$ over the Eastern United States of America. Although air traffic is much less extensive over Southeast Asia, the estimated contrail coverage is only slightly smaller than that over Europe and North America, probably because this region more often has ice-supersaturated air masses. These values represent the lower bound for the actual contrail coverage, however, because only contrails with distinct line shapes were analyzed. Aged contrails often cannot be distinguished from cirrus clouds (Minnis et al. 1998). The upper bound for aviationinduced changes in cirrus clouds may be deduced from the differential increase in cirrus cloud cover as done in the aforementioned studies of Minnis et al. (2000) and Boucher (1999). IPCC (1999) summarized their results and suggested that the upper bound is about $1.4 \%$ in the gross air traffic areas and $0.3 \%$ globally, which are 3 times higher than the lower bounds mentioned above.

The importance of contrails in changing the regional and global radiation budget has been estimated in several modeling studies. Fortuin et al. (1995) used a one-dimensional radiative model with a plain-parallel assumption and specified contrail microphysical properties and 
atmospheric conditions. They estimated that, with a $0.5 \%$ cloudiness, contrails may produce top-of-atmosphere (TOA) radiative forcing of -0.15 to $+0.30 \mathrm{~W} \mathrm{~m}^{-2}$ for the Atlantic flight corridor, comparable in magnitude to the forcing by aircraft-emitted greenhouse gases. Minnis et al. (1999) calculated the TOA radiative forcing for the year of 1992 with a similar approach and found a net global radiative forcing of $0.01 \mathrm{~W} \mathrm{~m}^{-2}$. The values are much higher for heavy air traffic regions, with maximum values of $0.71 \mathrm{~W} \mathrm{~m}^{-2}$ over Northeastern France and $0.58 \mathrm{~W}$ $\mathrm{m}^{-2}$ near New York. It is obvious that the current effect of contrails on climate is significant only over localized areas and perhaps for only a short term. Fortuin et al. (1995) and Strauss et al. (1997) suggested that the maximum instantaneous radiative forcing directly beneath a contrail (or assuming a $100 \%$ cloud cover) might range from $-30 \mathrm{~W} \mathrm{~m}^{-2}$ to $+60 \mathrm{~W} \mathrm{~m}^{-2}$. Such magnitudes of radiative forcing may result in surface temperature changes of a few $\mathrm{K}$. Using different radiative models, Liou et al. (1990) found a $1 \mathrm{~K}$ increase in surface temperature over most of the Northern Hemisphere if a 5\% contrail cloud cover is assumed. Strauss et al. (1997) then found a warming of $0.05 \mathrm{~K}$ using a $0.5 \%$ contrail cloud cover for a mid-European region. Although the global mean magnitude of radiative forcing from contrails is relatively small compared with the estimated anthropogenic greenhouse effect under current conditions, one should not ignore their importance because of the strong local effect and the expected rapid increase in air traffic activities.

Global air traffic flow, measured in revenue per passenger kilometers (RPK), has grown by a factor of 4.6 during the period of 1970-1995, about 2.4 times the average growth rates of gross domestic product (IPCC 1999). The highest growth occurred in the Asian Pacific region, increased by a factor of 20 during 1970-1995. In addition, the world market share of RPK in the Asian Pacific region in 1995 reached about 15\% according the data given in IPCC (1999), and is expected to increase further during the next decade. In fact, the highest growth rates of world air affic, either domestic or international, during the next decade are projected to occur in the Asian Pacific region (AEROCHEM 1995; ATAG 1997). Since contrail cover will increase as air traffic increases, the potential influence of contrails in this regional deserves special attention. This is particularly true for Taiwan because of its key geographic position pertaining to the major Asian/Pacific air traffic routes.

The wide range of values obtained by Fortuin et al. (1995) and others suggest that the estimation of radiative forcing have rather large uncertainties. Moreover, the sign of radiative forcing can either be positive or negative because of competition between longwave (warming) and shortwave (cooling) effects under different atmospheric conditions. In addition to the different ways of calculating radiative transfer, these model results also depend on assumed values for contrail cover and mean contrail optical depth, which are not well known and most likely have large spatial and temporal variations. Current estimations of contrail effects are based primarily on data applicable to the North America or Europe/Atlantic regions. To properly understand the problem for the Taiwan area, it is necessary to derive contrail parameters based on local conditions. This study attempted to estimate contrail radiative forcing over the Taiwan area with a somewhat different approach than those mentioned above. We first derived contrail frequency statistics by combining the flight frequency statistics obtained by Lin et al. (2001) and the probability of contrail occurrence according to local meteorological soundings. Twelve types of contrails were classified according to the above statistics and then 
simulated using a two-dimensional cirrus model with detailed microphysical treatment. Shortwave and longwave radiative transfer for each contrail type could thus be calculated. Finally, a composite of these results was derived in obtaining the regional distribution of contrail radiative forcing.

\section{CONTRAIL FREQUENCY STATISTICS}

\subsection{Contrail Formation Criterion}

Contrails occur as a result of the mixing of hot and moist engine exhaust with cold and moist ambient air, which may produce supersaturation when the right mix proportion is reached. Such a mixing-cloud process is somewhat more complicated than those (such as mixing fog or steam) commonly observed in nature, because two phase-change stages are involved during contrail formation. Figure 3 shows the air parcel mixing line (thin lines $\mathbf{A}$ and $\mathbf{B}$ ) on the phase diagram of water vapor versus liquid water (thick solid curve) and ice (dotted curve). The lower-left end of the mixing lines represents the properties (temperature and vapor pressure) of the ambient air. The far-right end, where lines $\mathbf{A}$ and $\mathbf{B}$ eventually converge (off scale), represents the properties of the fresh aircraft exhaust. As the ambient air gradually dilutes the exhaust, its temperature and vapor pressure change linearly by following the mixing line toward the lower-left end. For a contrail to form, the mixing line (e.g., line A) must cross the water saturation curve $e_{s, w}$ to produce supersaturation so that particles in the mixed exhaust can activate into cloud drops by condensation. Due to the low temperatures, cloud drops then quickly freeze and form ice particles. Note that, because of a lack of ice nuclei at high altitudes and in aircraft exhausts, a supersaturation with respect to ice does not induce ice formation. As a result, all mixing along the lines positioned below line $\mathbf{B}$ in Fig. 3 does not form contrails (e.g., points $\mathbf{a}$ or $\mathbf{b}$ ). Thus, contrail will form for ambient conditions at point $\mathbf{c}$ and will not form at point $\mathbf{b}$ even though they have the same temperature. Note that, if the airplane is flying inside a natural cirrus cloud $\left(e=e_{\mathrm{s}, \mathrm{i}}\right)$, the thresholds are a bit lower because the evaporation of cirrus ice may provide additional water vapor. The lifetime of contrails also depends on the ambient conditions. If the ambient humidity is above ice saturation (e.g., point $\mathbf{c}$ ), ice particles will grow and the contrail may persist; otherwise (e.g., point d) contrails will dissipate. The conditions for the formation of persistent and dissipating contrails are highlighted with dark and light shadings, respectively, in Fig. 3.

\subsection{Formation Probability}

Following these principles, we analyzed the 1993-1997 Ban-Chiao (46692) sounding to determine the climatological probability of contrail-favorable atmospheric conditions ("formation probability" hereafter). The formula used here (see Lin 2000) for determining contrail types (persistent, dissipating, or none) is similar to the Schmidt/Appleman's criterion commonly applied in other studies (cf. Schumann 1996). Note that relative humidity data at high altitudes can be 20 to $30 \%$ too low under unfavorable conditions (Pratt 1985), so the following analyses have some inherent bias. Figure $4 \mathrm{a}$ and $4 \mathrm{~b}$ show the formation probability 


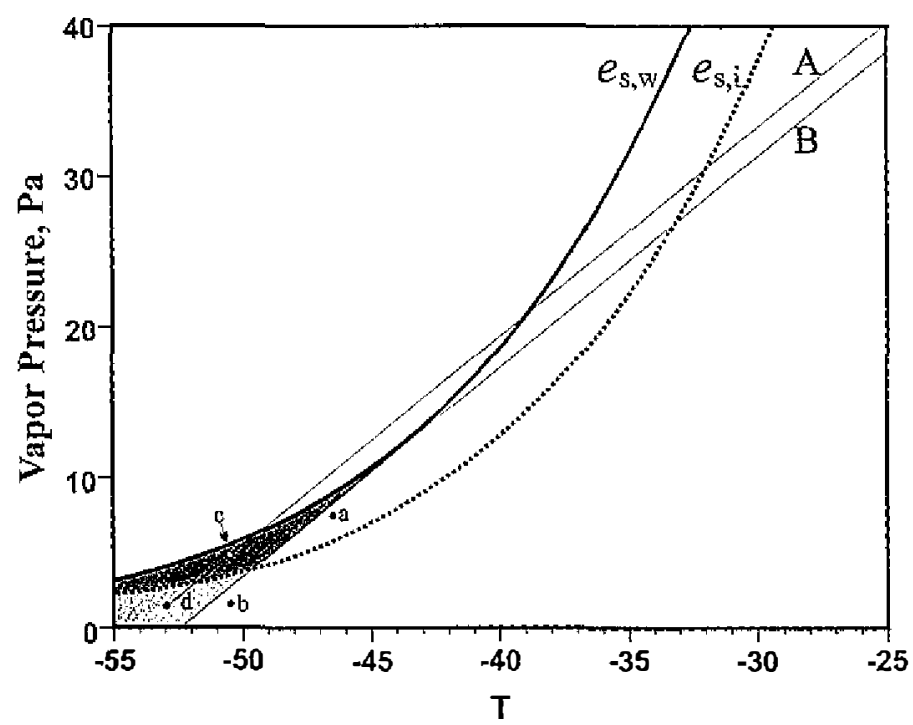

Fig. 3. Overlaid on the phase diagram of water are the dilution paths (mixing lines) along which the aircraft exhaust mixes with the ambient air. The lower-left end of the mixing lines represents the ambient air, and the farright end where lines $\mathbf{A}$ and $\mathbf{B}$ eventually meet (off scale) represents the fresh aircraft exhaust. The thick-solid and thick-dotted curves are the saturation vapor pressure over liquid water $\left(e_{\mathrm{s}, \mathrm{w}}\right)$ and over ice $\left(e_{\mathrm{s}, \mathrm{i}}\right)$, respectively. Line B, tangent to curve $e_{\mathrm{s}, \mathrm{w}}$, is the threshold mixing line below which contrails cannot occur. Areas with dark/light shadings indicate conditions suitable for persistent/dissipating contrail formation. Note that ambient conditions above the $e_{\mathrm{s}, \mathrm{w}}$ curve (also suitable for persistent contrail formation) rarely occur because natural cirrus would have formed already.

of dissipating and persistent contrails at different altitudes and seasons. The most favorable altitudes for dissipating contrails to form is between 14 and $16 \mathrm{~km}$, with a maximum annual mean probability reaching $92 \%$ at $14 \mathrm{~km}$. Persistent contrails form most favorably at $16 \mathrm{~km}$, with a maximum annual mean probability reaching $12 \%$. Apparently, the most favorable contrail-forming conditions for the Taiwan area occur in the coldest air near the tropopause. One should pay particular attention to the formation probability below $13 \mathrm{~km}$ where most commercial airplanes fly. At these lower altitudes, the formation probabilities of both dissipating and persistent contrails have a minor peak at $12 \mathrm{~km}$, and are insignificant below $10 \mathrm{~km}$.

The seasonal distribution of dissipating contrail probability (averaged between 9 and 23 $\mathrm{km}$ ) is higher during the winter and lower in the summer, with a maximum of $49 \%$ occurring in December and a minimum of 35\% in July. Persistent contrails have a somewhat different seasonal variation: the column-averaged (between 9 and $23 \mathrm{~km}$ ) formation probability is the highest during March (7.1\%) and May (6.9\%), and the lowest during October $(0.87 \%)$. The absolute vertical and seasonal maximum formation probability is $98 \%$ at $14 \mathrm{~km}$ during Octo- 
(a)
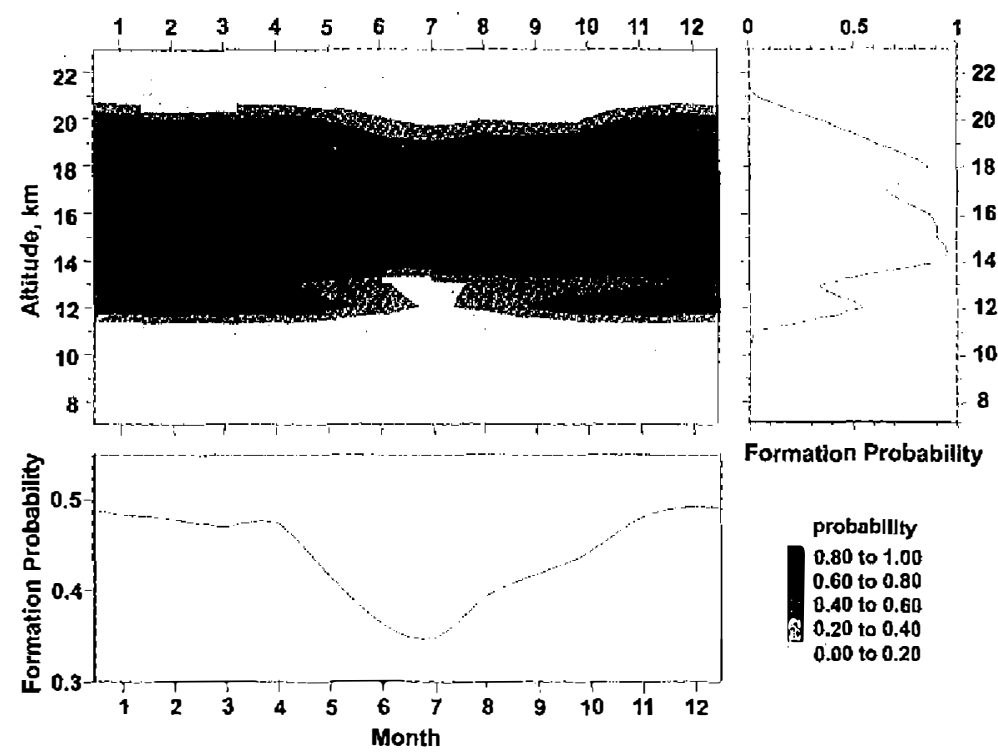

Formation Probability probabllity 0.80 to 1.00 0.60 to 0.80 0.40 to 0.6 0.40 to 0.60 0.00 to 0.20

(b)
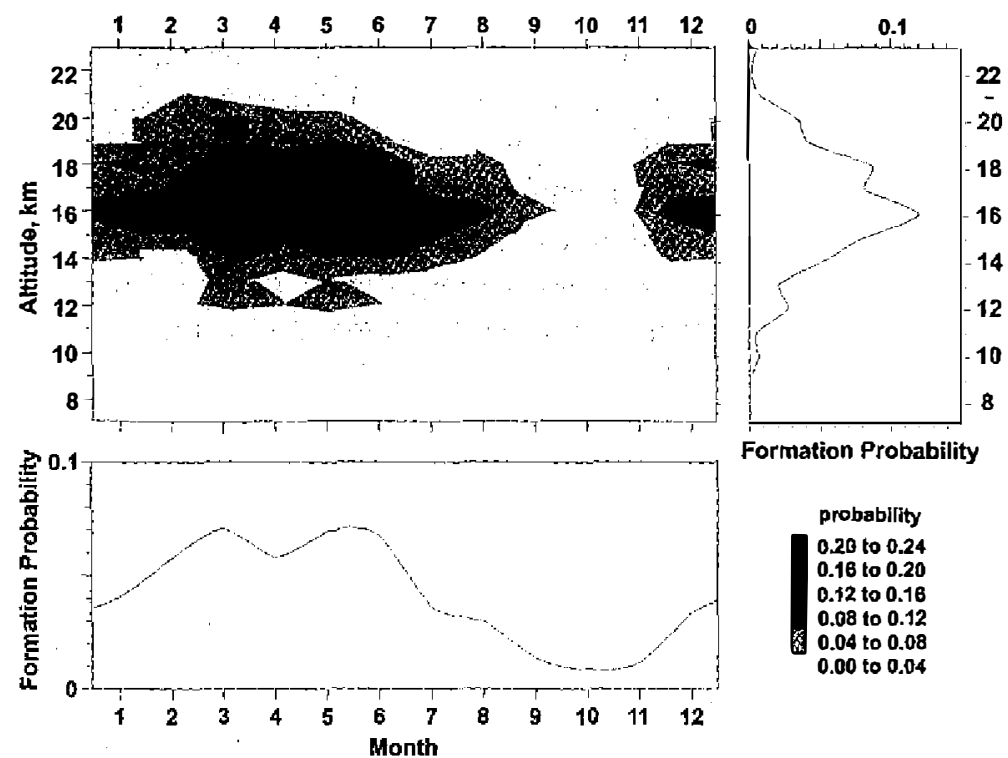

Formation Probability

probability

0.20 to 0.24

0.16 to 0.20

0.12 to 0.16

0.08 to 0.12

0.04 to 0.08

0.00 to 0.04

Fig. 4. Formation probability of (a) dissipating contrails and (b) persistent contrails. The upper-left panel gives the probability as a function of both altitude and month of the year, with values indicated by the shade-bars on the lower-right panel. The upper-right panel gives the annual average formation probability at each height level, and the lower-left panel is the monthly values averaged over heights between 9 and $23 \mathrm{~km}$. 
ber for dissipating contrails and $23 \%$ at $16 \mathrm{~km}$ during June for persistent contrails. . The annual average formation probability between 9 and $23 \mathrm{~km}$ is $44 \%$ for dissipating contrails and 10 times less (4.1\%) for persistent contrails. At cruising altitudes of $9 \sim 13 \mathrm{~km}$, the probabilities are $18 \%$ and $1.2 \%$, respectively. In comparison, Sausen et al. (1998) found a $16 \%$ global coverage of air masses suitable for contrail formation. This ratio is highest in the tropical upper troposphere.

\subsection{Occurrence Frequency}

The formation probability discussed above does not represent the frequency of contrail occurrence because most aircraft fly in altitudes below $13 \mathrm{~km}$. To obtain the contrail "occurrence frequency" one needs to factor in the vertical distribution of all flights. Next we estimated the occurrence frequency by combining the formation probability with the international flights vertical distribution investigated by Lin et al. (2001). Note that domestic flights in Taiwan normally fly at altitudes below $9 \mathrm{~km}$ and therefore do not produce contrails. Figure 5 shows the normalized (i.e., resulted from a single aircraft) occurrence frequency of dissipating and persistent contrails. To get the total occurrence frequency, one needs to multiply the normalized occurrence frequency by the actual flight frequency in each flight corridor (see Section 4). Figure 5a shows that dissipating contrails should occur mostly at the 11 and $12-\mathrm{km}$ levels, and none above $13 \mathrm{~km}$ (no flights) or below $9 \mathrm{~km}$ (no formation probability). Different from the formation probability shown in Fig. 4 a, the most favorable time to see dissipating contrails is in March and next favorable time is in January. July is still the least likely month for contrails to occur in the Taiwan area. For all aircraft flying at 11 or $12 \mathrm{~km}$, about $2.2 \%$ will produce dissipating contrails on an annual average, which gives a contrail frequency of about 3 per day in the busiest A1 route (flight frequency of 147 per day; cf. Lin et al. 2001). The highest normalized occurrence frequency is $3.4 \%$ at the $11-\mathrm{km}$ level during March.

The occurrence frequency for persistent contrails distributes differently from that of dissipating contrails. In Fig. 5b the maximum annual mean occurrence frequency of persistent contrails is $0.18 \%$ located at $11 \mathrm{~km}$, about $0.5 \sim 1 \mathrm{~km}$ lower than that of dissipating contrails. The most favorable month for persistent contrails to occur is February, with a maximum column accumulated occurrence frequency reaching $1.1 \%$ per aircraft. For the A1 route, the occurrence frequency of persistent contrails should be about 1.5 day $^{-1}$ in February. October, July and August are the least likely months for persistent contrail to occur. On an annual a verage, $0.36 \%$ of the international flights will produce persistent contrails. The seasonal variation in contrail occurrence frequency over the Taiwan area is similar to the results of Minnis et al. (1997) who indicated that the contrail frequency peaks around February/March and is at a minimum during July over the continental United States.

\section{CONTRAIL CLASSIFICATION}

As mentioned in Section 1, current modeling studies on the regional or global radiative effects of contrails tend to apply specified contrail microphysical and radiative properties for all regions or seasons. In this study we applied a somewhat different approach by deriving 
(a)

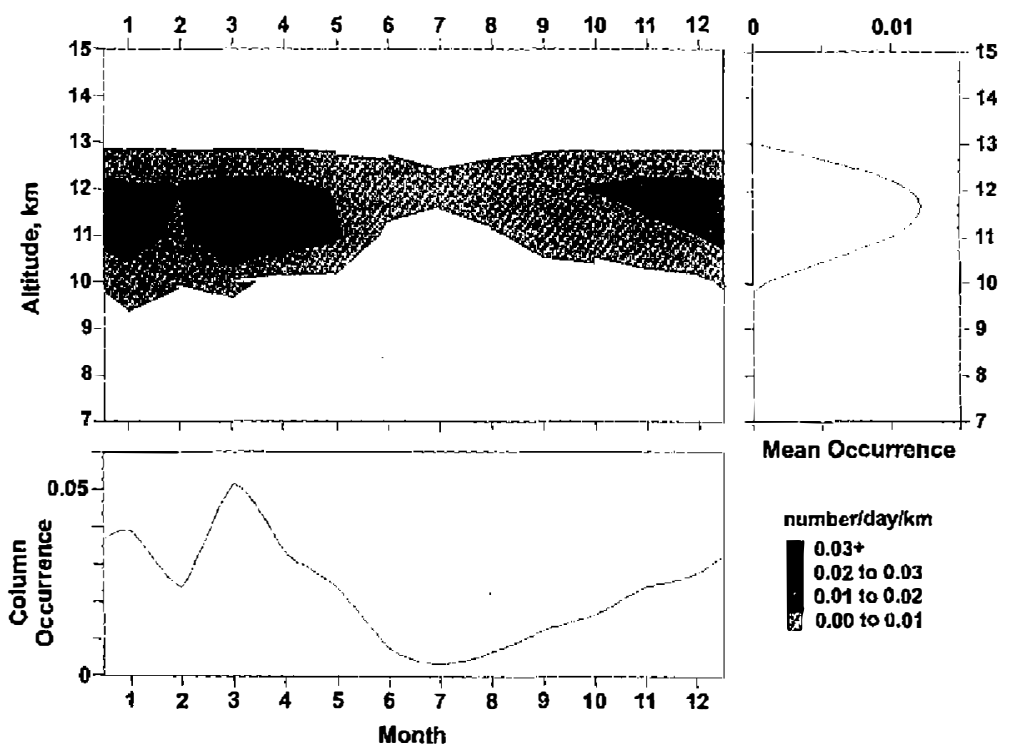

(b)

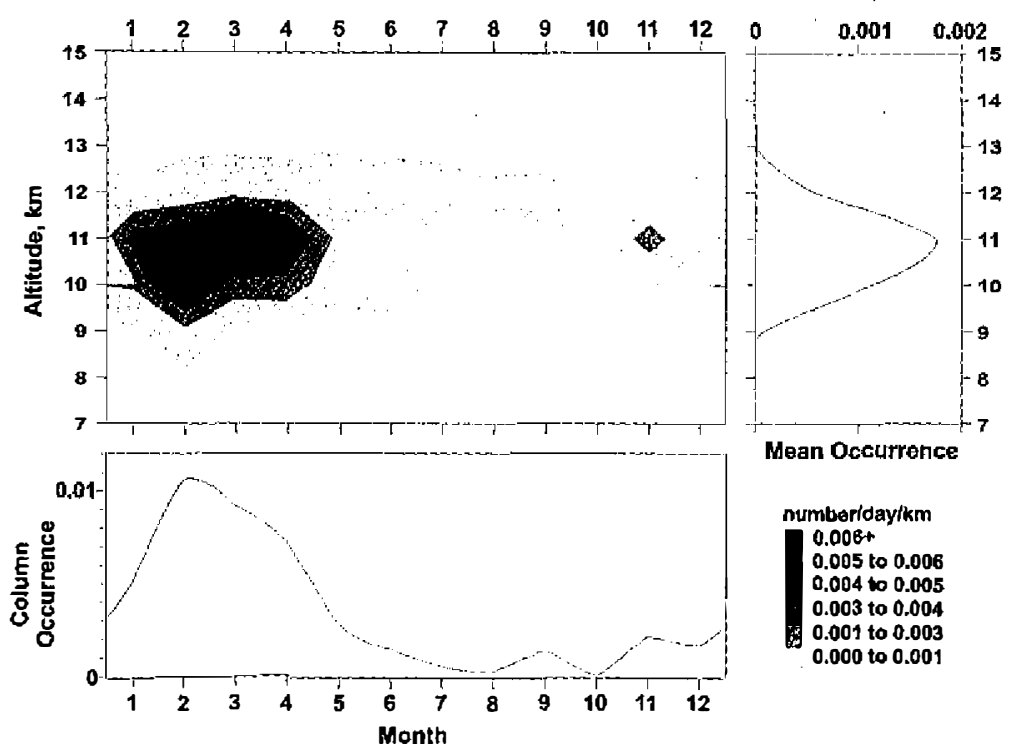

Fig. 5. Normalized occurrence frequency for (a) dissipating contrails and (b) persistent contrails. The upper-left panel is contrail occurrence frequency (number $/$ day $/ \mathrm{km}$ ) as a function of altitude and month of the year, with values indicated by the shade-bars on the lower-right panel. The upperright panel gives the annual average frequency (in number/day $/ \mathrm{km}$ ) at each height level, and the lower-left panel is the monthly formation frequency (in number/day) integrated over all heights. 
contrail properties for different atmospheric conditions using a two-dimensional cirrus model, which considers detailed dynamic, microphysical and radiative processes in a $1.5 \mathrm{~km}$ (horizontal) by $1 \mathrm{~km}$ (vertical) domain. Descriptions of this model can be found in Chen and Lin (2001) and will not be elaborated here. Since it is not possible to consider all of the details, we simplified the work by classifying contrails into 12 types according to the major conditions of formation (i.e., ambient relative humidity with respective to ice RHi and temperature $T$ ). In this classification, types 1 through 9 pertain to dissipating contrails, whereas types 10 through 12 pertain to persistent contrails. The mean atmospheric conditions $\left(\mathrm{RH}_{\mathrm{i}}\right.$ and $\left.T\right)$ and occurrence percentage for each contrail type were determined from the same data set that produced Fig. 5.

Using the mean $\mathrm{RH}_{\mathrm{i}}$ and $T$ shown in Table 1 as initial conditions, we simulated the time

Table 1. Classification of contrail-forming atmospheric conditions. The ordinate is relative humidity with respect to ice $\left(\mathrm{RH}_{\mathrm{i}}\right)$, classified into 4 categories with $60 \%, 80 \%$ and $100 \%$ as dividers; the abscissa is air temperature, classified into 3 categories with $-52^{\circ} \mathrm{C}$ and $-55^{\circ} \mathrm{C}$ as dividers. The percentage of occurrence for each type is indicated in the parentheses. Also listed are the mean conditions of each type, analyzed from the sounding climatology.

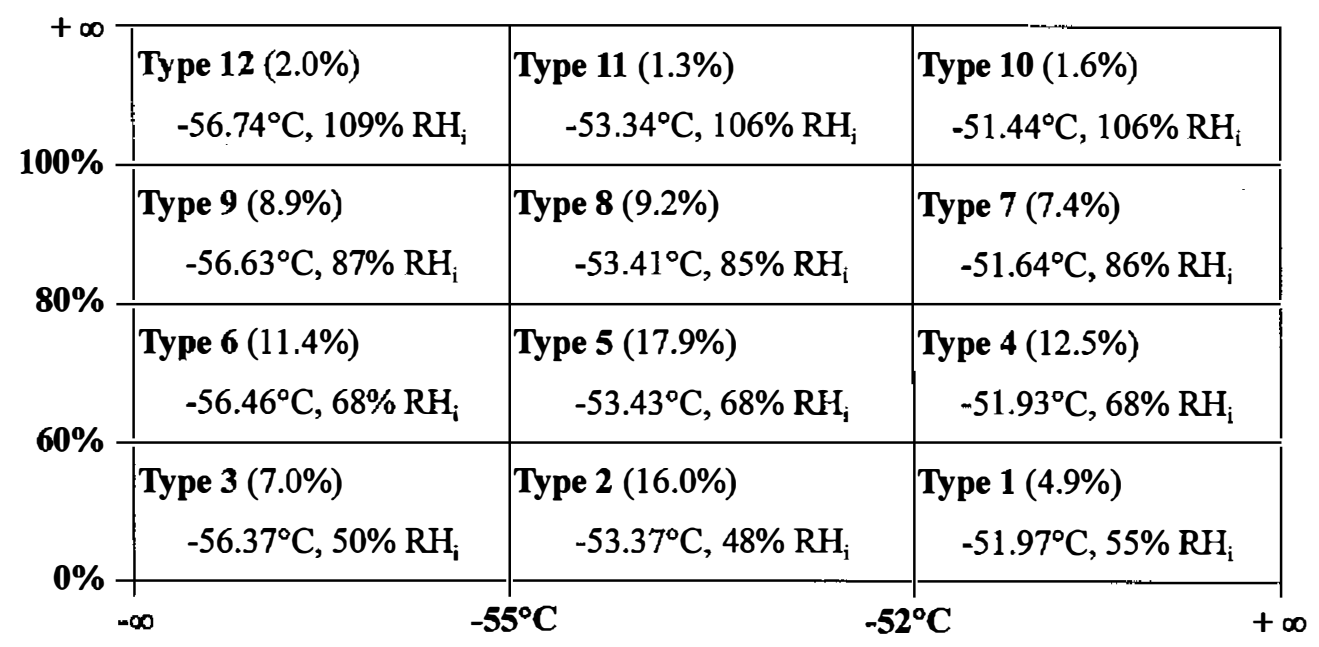

evolution of the microphysical and radiative properties for the 12 contrail types. Each simulation was carried out for only 12 hours because that is the maximum length of time one atmospheric sounding should represent. In order to focus on the regional radiative effects, only the domain-averaged contrail properties are discussed here. The reader is referred to Chen and Lin (2001) for other details about the two-dimensional contrail simulation. Figure 6 shows the time evolution of parameters relevant to the radiative effects. Since the evolution patterns of contrail properties are similar within the gross categories (dissipating or persistent), we selected contrail type 5 to represent dissipating contrails and type 11 to represent persistent 
contrails to avoid clutter in the figures. The dissipating contrail initially has a mean effective radius $r_{\mathrm{e}}$ of $2.5 \mu \mathrm{m}$, which decreased only slightly with time. However, the contrail width decreased significantly and evanesced completely after about 7 hours. Characterized by its growth after formation, the persistent contrail quickly expanded to $1 \mathrm{~km}$ wide within about 2 hours then, with a slower growth, reached about $1.3 \mathrm{~km}$ wide at the end of the simulation. It's mean effective radius reached a maximum of $8.5 \mu \mathrm{m}$ in 2 hours then, due to fallout of the larger particles, decreased to about $5 \mu \mathrm{m}$ toward the end of the simulation. Chlond (1996) obtained similar values in a detailed contrail simulation. Betancor Gothe and Grassl (1993) also showed that the longwave characteristics of contrails only match satellite observations for crystal sizes around 4 to $6 \mu \mathrm{m}$. Although some observational studies found significantly greater values (e.g., $15 \sim 18 \mu \mathrm{m}$ in Gayet et al. 1996), the effective radii obtained in this study seems

(a)

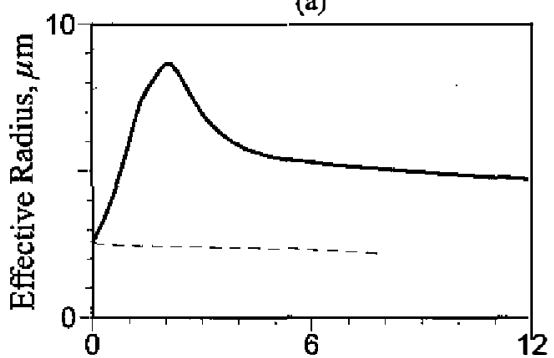

(c)

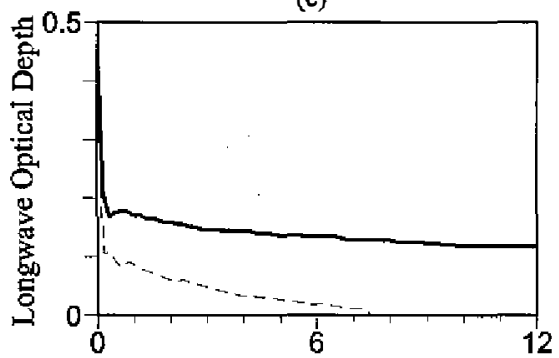

(e)

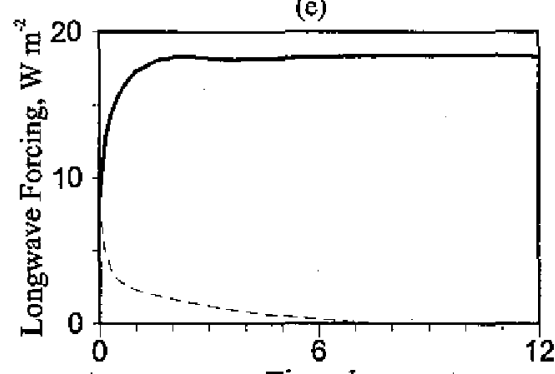

Time, hr (b)

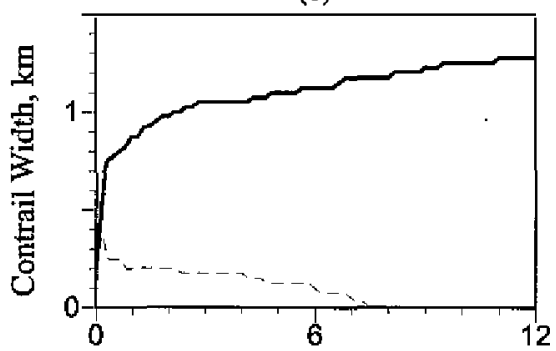

(d)

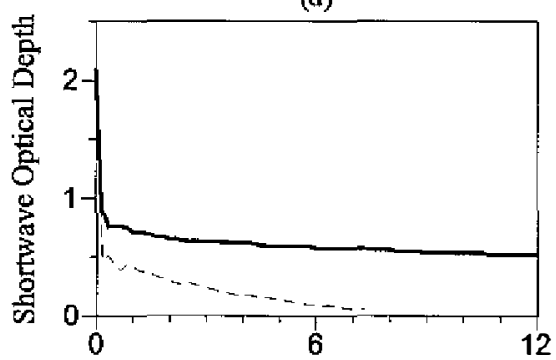

(f)

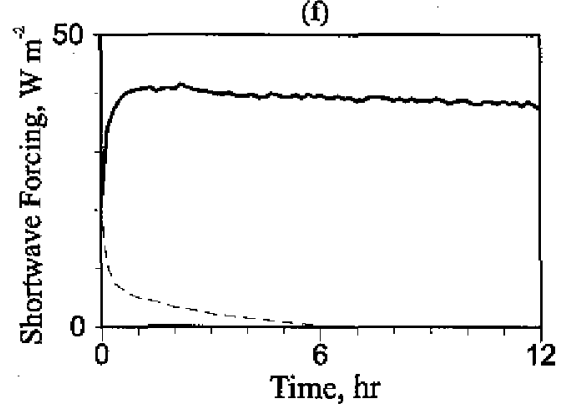

Fig. 6. Time evolution of the domain-averaged properties of type 5 (dotted curve) and type 11 (solid curve) contrails: (a) effective radius, (b) contrail width, (c) longwave optical depth, (d) shortwave optical depth, (e) longwave radiative forcing (warming), and (f) shortwave radiative forcing (cooling). 
to be within a reasonable range. Due to strong turbulent mixing and dilution in the first few minutes, the longwave and shortwave optical depths $\left(\tau_{L}\right.$ and $\left.\tau_{S}\right)$ of both types of contrails experience an initial sharp drop, then decrease gradually with time. The mean $\tau_{L}$ and $\tau_{s}$ of the type 5 dissipating contrail during its lifetime are 0.051 and 0.450 , respectively. Values for the persistent contrail are much higher, with a mean of 0.143 in the longwave and 0.8253 in the shortwave.

Figures $6 \mathrm{e}$ and $6 \mathrm{f}$ show the domain-averaged effects of contrails on top-of-atmosphere (TOA) radiation fluxes ("radiative forcing" hereafter). Here, the longwave radiative forcing $\left(F_{\mathrm{L}}\right)$ is defined as the decrease in TOA longwave radiation flux (thus a warming effect to the surface). The shortwave radiative forcing $\left(F_{s}\right)$ is defined here as the fraction of the solar flux reflected by the contrail (thus a cooling effect to the surface). Therefore, both $F_{L}$ and $F_{S}$ always have positive values. Note that the cloud reflectance is calculated with the Monte Carlo method (cf. Chen and Lin 2001) and counting in solar zenith angle and azimuth angle relative to the contrails. In Fig. $6 \mathrm{f}$ only zero zenith angle (sun directly overhead) situation is demonstrated. The $F_{\mathrm{L}}$ of the dissipating contrail is initially $8.3 \mathrm{~W} \mathrm{~m}^{-2}$ over the $1.5-\mathrm{km}$ model domain, then decreases to zero as the contrail vanishes. On the other hand, the $F_{L}$ of the persistent contrail increases quickly from $8.3 \mathrm{~W} \mathrm{~m}^{-2}$ to over $18 \mathrm{~W} \mathrm{~m}^{-2}$ in 2 hours, and remains rather constant afterwards. As can be expected, the lifetime-mean $\mathrm{F}_{\mathrm{L}}$ of the persistent contrail $\left(16 \mathrm{~W} \mathrm{~m}^{-2}\right)$ is much higher than that of the dissipating contrail $\left(1.1 \mathrm{~W} \mathrm{~m}^{-2}\right)$. The variation in the shortwave radiative forcing has similar patterns as those of the longwave forcing but with different magnitudes. The mean $F_{\mathrm{s}}$ is $2.6 \mathrm{~W} \mathrm{~m}$. for the dissipating contrail and $39.0 \mathrm{~W} \mathrm{~m}^{-2}$ for the persistent contrail. The latter value is very similar to the result of Sassen (1997) who observed a reduction in global solar irradiance of $\sim 40 \mathrm{~W} \mathrm{~m}^{-2}$ when the contrail is directly under the sun.

Table 2 shows the mean properties of all 12 types of contrails. It is obvious that significant differences exist between the properties of dissipating contrails and persistent contrails. All of these differences lead to the contrast in their radiative properties. Greater than 10 times higher radiative forcing on average in both the longwave and shortwave bands by persistent contrails over dissipating contrails. Nevertheless, one should not overlook the importance of dissipating contrails, because they have a much higher occurrence frequency. We will further apply the above results in estimating the radiative forcing of contrails on a regional scale, and show that the contribution from dissipating contrails is indeed greater than that of persistent contrails.

\section{ESTIMATION OF REGIONAL RADIATIVE FORCING}

\subsection{Advection Effect}

Although commercial aircraft usually fly at rather specific locations (aircraft corridors), the contrails they produce can be advected afar due to the typically strong upper wind. To estimate the regional radiative effects, we need to convert the time variation of contrail properties discussed in the last section into a spatial variation according to the distribution of upper wind speed. From the Ban-Chiao sounding data we found that winds at contrail-forming 
Table 2. Properties of the 12 types of contrail averaged over the 12-hour simulation time. These properties include effective radius $\left(r_{\mathrm{c}}\right)$, contrail width $(W)$, ice water path $(u)$, longwave $\left(\tau_{\mathrm{L}}\right)$ and shortwave $\left(\tau_{\mathrm{s}}\right)$ optical depths, longwave $\left(F_{\mathrm{L}}\right)$ and shortwave $\left(F_{\mathrm{S}}\right)$ radiative forcing, and occurrence percentage $(Q)$.

\begin{tabular}{crrrrrrrr}
\hline Type & $r_{\mathrm{e}}, \mu \mathrm{m}$ & $W, \mathrm{~m}$ & $u, \mathrm{~g} \mathrm{~m}^{-2}$ & \multicolumn{1}{c}{$\tau_{\mathrm{L}}$} & $\tau_{\mathrm{s}}$ & $F_{\mathrm{L}}, \mathrm{W} \mathrm{m}^{-2}$ & $F_{\mathrm{S}}, \mathrm{W} \mathrm{m}^{-2}$ & $Q, \%$ \\
\hline 1 & 2.39 & 137 & 0.253 & 0.049 & 0.225 & 0.79 & 2.33 & 4.9 \\
2 & 2.42 & 146 & 0.351 & 0.068 & 0.325 & 1.02 & 3.05 & 16.0 \\
3 & 2.32 & 149 & 0.273 & 0.054 & 0.250 & 1.18 & 2.55 & 7.0 \\
4 & 2.35 & 168 & 0.282 & 0.055 & 0.225 & 1.27 & 2.98 & 12.5 \\
5 & 2.38 & 158 & 0.260 & 0.051 & 0.250 & 1.10 & 2.56 & 18.0 \\
6 & 2.34 & 272 & 0.239 & 0.047 & 0.225 & 1.67 & 3.88 & 11.4 \\
7 & 2.42 & 352 & 0.270 & 0.053 & 0.250 & 1.01 & 4.55 & 7.4 \\
8 & 2.46 & 311 & 0.310 & 0.060 & 0.275 & 2.29 & 5.06 & 9.1 \\
9 & 2.47 & 366 & 0.503 & 0.098 & 0.475 & 4.24 & 11.08 & 9.0 \\
10 & 6.08 & 1368 & 0.914 & 0.129 & 0.525 & 19.14 & 41.06 & 1.6 \\
11 & 5.54 & 1093 & 0.942 & 0.143 & 0.625 & 16.10 & 39.01 & 1.3 \\
12 & 5.53 & 1167 & 0.879 & 0.133 & 0.650 & 16.60 & 54.03 & 2.0 \\
\hline
\end{tabular}

levels are predominately Westerly winds (over $80 \%$ of the winds are from the West, and about $15 \%$ are from the Southwest). We therefore consider only the East-West (U) components of the winds. Figure 7 shows the frequency distribution of the U-component wind speed for all contrail-forming situations according to the 5-year sounding data. One can see predominately Westerly winds, with a maximum frequency at about $42 \mathrm{~m} \mathrm{~s}^{-1}$.

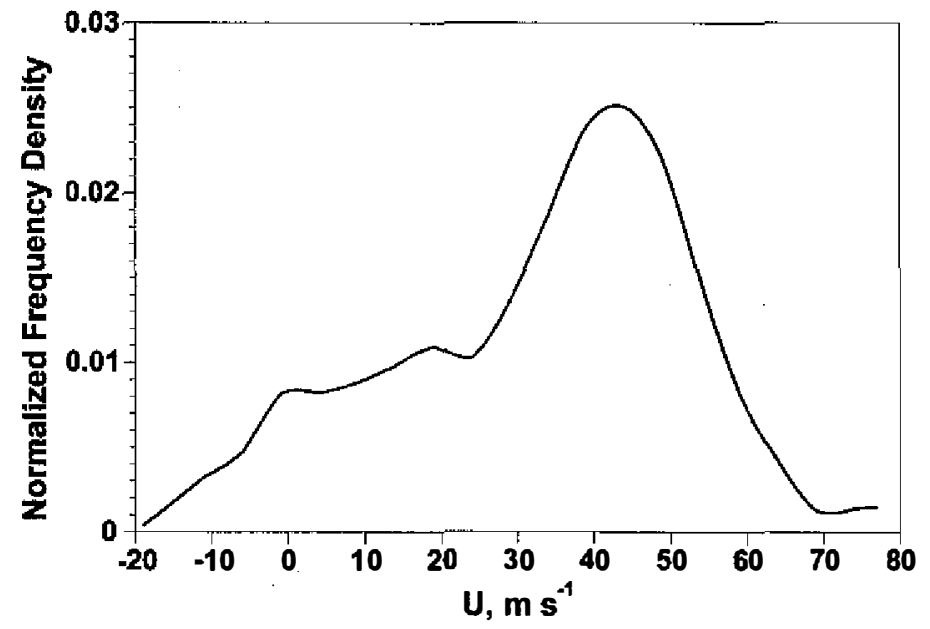

Fig. 7. Normalized distribution of the U-component winds for all contrailforming conditions during 1993-1997. The ordinate is the normalized frequency density (fraction of occurrence per unit wind speed interval). 
Figure 8 shows the latitudinal (East-West) variation of single-contrail properties (types 5 and 11) converted from Fig. 6 according to the wind distribution shown in Fig. 7. Note that the cloud width in Fig. 6b is further converted into the cloud coverage in Fig. 8b. Except for the effective radius, all contrail properties decrease with distance further away from the origin (flight path). The distributions are mirrored at the origin point but asymmetrical toward the West because of a higher frequency of West wind than East wind. The $r_{\mathrm{e}}$ peaks on both sides of the origin point correspond to the maximum in time evolution shown in Fig. 6. Wind advection causes the contrails to drift away from the flight course so that the radiative forcing is distributed over a broader domain than stationary contrails. By comparing the model domain of $1.5 \mathrm{~km}$ with the regional domain of $1600 \mathrm{~km}$, one can see why the magnitudes of
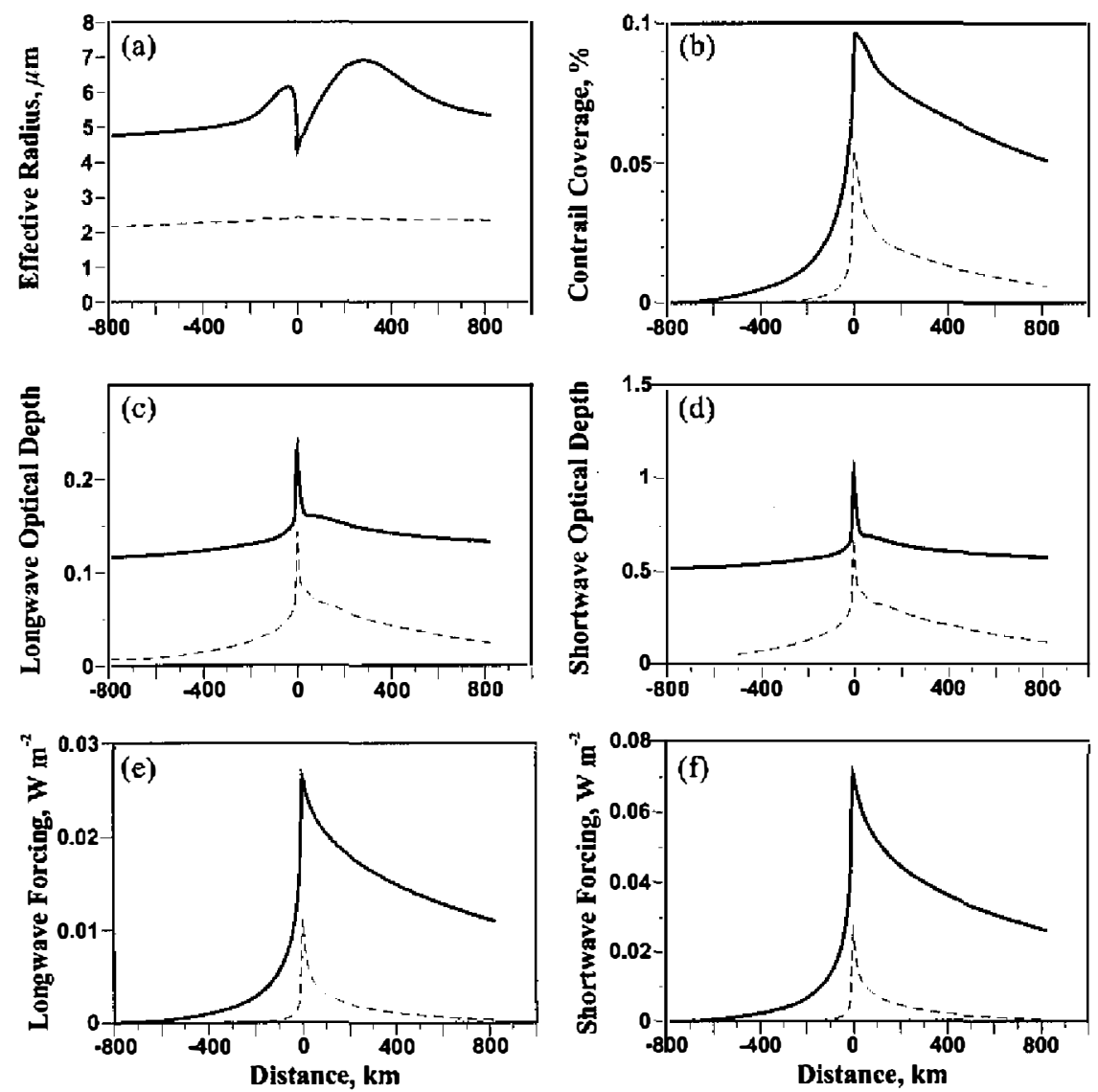

Fig. 8. Spatial (latitudinal) variation of the domain-averaged properties of type 5 (dotted curve) and type 11 (solid curve) contrails. (a) effective radius, (b) contrail coverage, (c) longwave optical depth, (d) shortwave optical depth, (e) longwave radiative forcing (warming), and (f) shortwave radiative forcing (cooling). The origin of the abscissa represents the position of the flight path. 
radiative forcing in Fig. 8 are about 1000 times smaller than those in Fig. 6. Note that we have taken into account the solar flux incidence angles in calculating shortwave radiative forcing by classifying the annual solar zenith angle and azimuth angle relative to the contrails into 16 categories. The overall shortwave radiative forcing is then obtained by weighting the radiative forcing with the occurrence probability of each category.

\subsection{Regional Annual Means}

By mapping Figs. 8e and $8 \mathrm{f}$ onto all flight routes and multiplying the values by the flight frequencies at each contrail-forming altitude, we obtained the radiative effects over the Taipei Flight Information Region (FIR). Taking contrail types 5 and 11 as examples, we will first discuss the daily effects from different types of contrails (i.e., assuming that only one type of contrail may occur each day). Note that shortwave radiative forcing exist only during the daytime, whereas longwave radiative forcing operates both day and night. In order to obtain the net radiative effects, we applied only the daytime frequency (accounts for $66 \%$ or the total) of international flights in obtaining the longwave and shortwave radiative forcing in Figs. 9 and 10. As shown in Figs. 9 and 10, the overall spatial distributions of the longwave and shortwave radiative forcing are very similar. Stronger radiative effects occur along the flight corridors and their downwind sides. From the distribution pattern one can also see that the advection of contrails to the downwind side is more pronounced for the persistent contrails due to their longer lifetimes. Thus, a large area of significant radiative forcing exists just south of Taiwan, where contrails from 4 flight corridors may coexist. The average regional longwave forcing is $0.08 \mathrm{~W} \mathrm{~m}^{-2}$ for the dissipating contrail and $0.68 \mathrm{~W} \mathrm{~m}^{-2}$ for the persistent contrail. In the shortwave forcing, the regional averages $\left(0.19\right.$ and $\left.1.67 \mathrm{~W} \mathrm{~m}^{-2}\right)$ are about 2.4 times greater. The values are much higher over localized areas, with local maximums reaching 8 times of the regional average for the dissipating contrails and 3 times for the persistent contrails.

The absolute values of daytime radiative forcing are greater in the shortwave than in the longwave for all contrail types, meaning that daytime contrails always produce a net cooling effect. On the other hand, nighttime contrails necessarily produce a net warming effect. Therefore, contrails have the effect of moderating diurnal temperature variations. By considering the daytime to nighttime flight ratio, one can get a net cooling effect over a 24 -hr period according to our results. The regional average of the net daily effect is $-0.03 \mathrm{~W} \mathrm{~m}^{-2}$ for dissipating contrails and $-0.33 \mathrm{~W} \mathrm{~m}^{-2}$ for persistent contrails, with local maximums reaching -0.31 and $-0.97 \mathrm{~W} \mathrm{~m}^{-2}$, respectively. Daily effects are much higher than the annual averages because contrail-forming conditions do not exist all the time. Figure 11 shows the net regional radiative effect calculated with the consideration of different radiative properties and annual occurrence probabilities for all 12 types of contrails. All but the northwest comer of the area shown in Fig. 11 overlaps with the Taipei Flight Information Region (FIR). The net effect is a cooling of $-0.006 \mathrm{~W} \mathrm{~m}^{-2}$ over the whole domain, and may reach a local maximum of $-0.027 \mathrm{~W}$ $\mathrm{m}^{-2}$. These values are somewhat lower than the global values estimated by Fortuin et al. (1995). Our calculation also shows that the contribution to regional radiative forcing (in both longwave and shortwave) by all dissipating contrails is about 2 times that by persistent contrails. 
Type 5, longwave

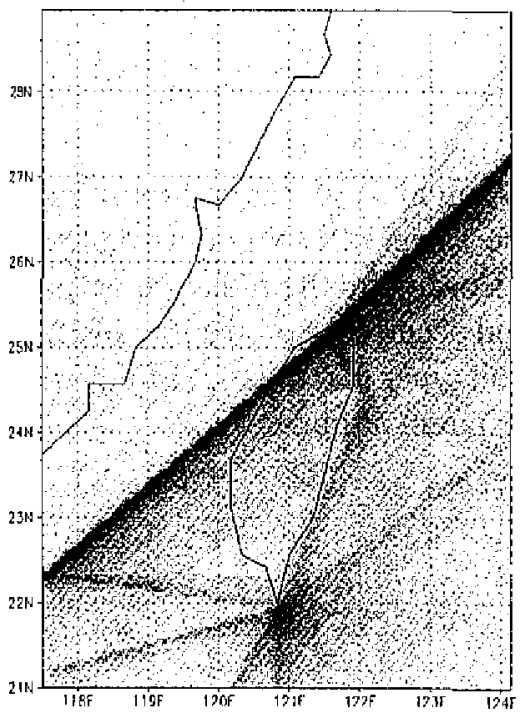

Type 11, longwave

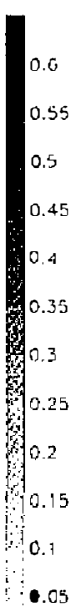

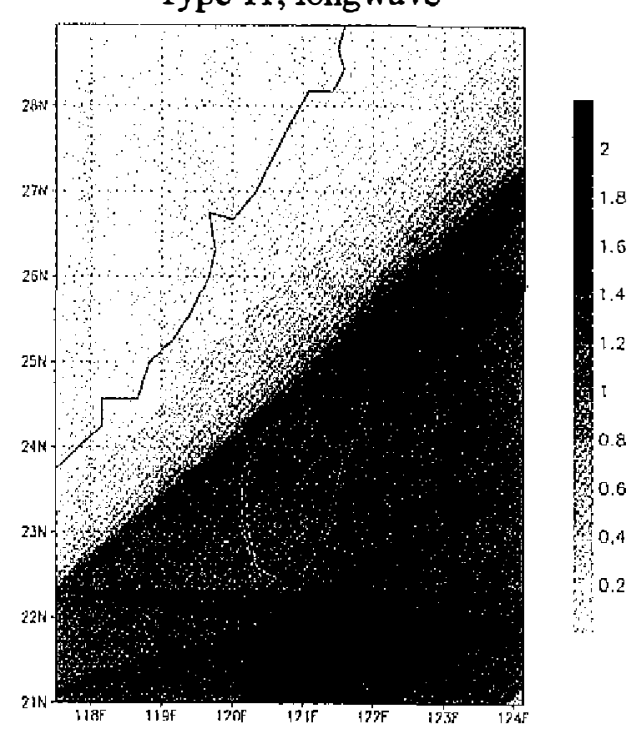

Fig. 9. Daytime longwave radiative forcing $\left(\mathrm{W} \mathrm{m}^{-2}\right)$ by dissipating contrails (type 5) and persistent contrails (type 11).

Type 5, shortwave

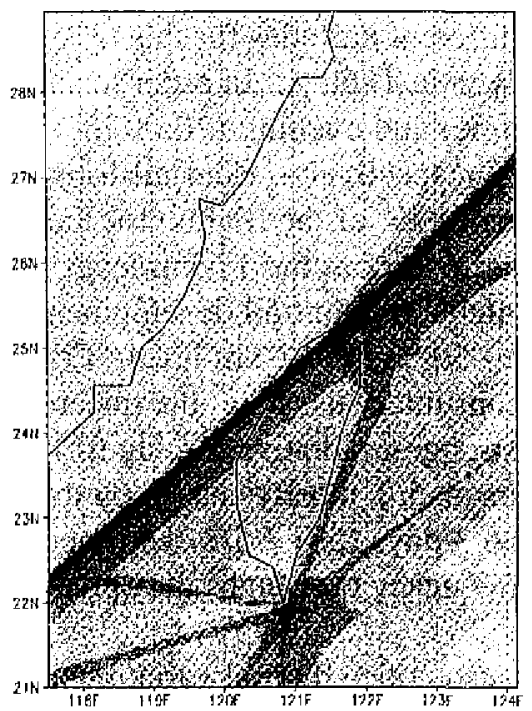

Type 11, shortwave

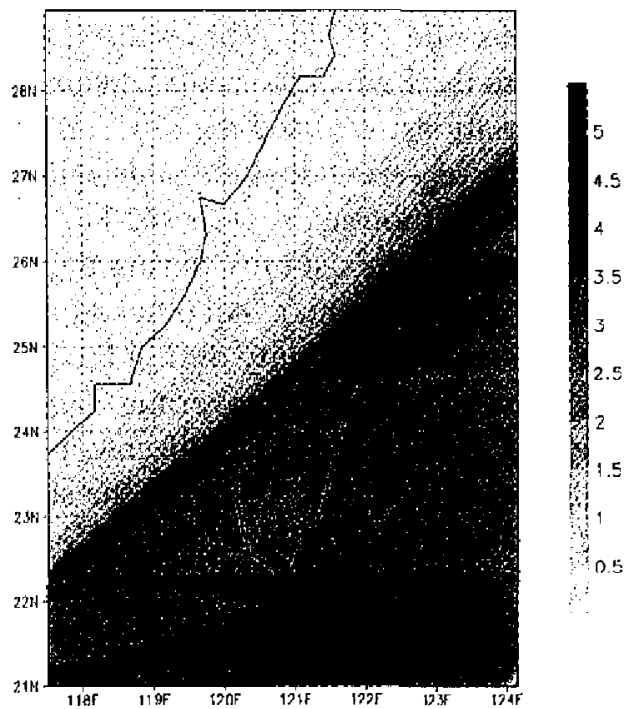

Fig. 10. Daytime shortwave radiative forcing $\left(\mathrm{W} \mathrm{m}^{-2}\right)$ by dissipating contrails (type 5) and persistent contrails (type 11). Note that absolute values are shown to represent reflected solar radiation, so the flux direction is opposite of those in Fig. 9. 


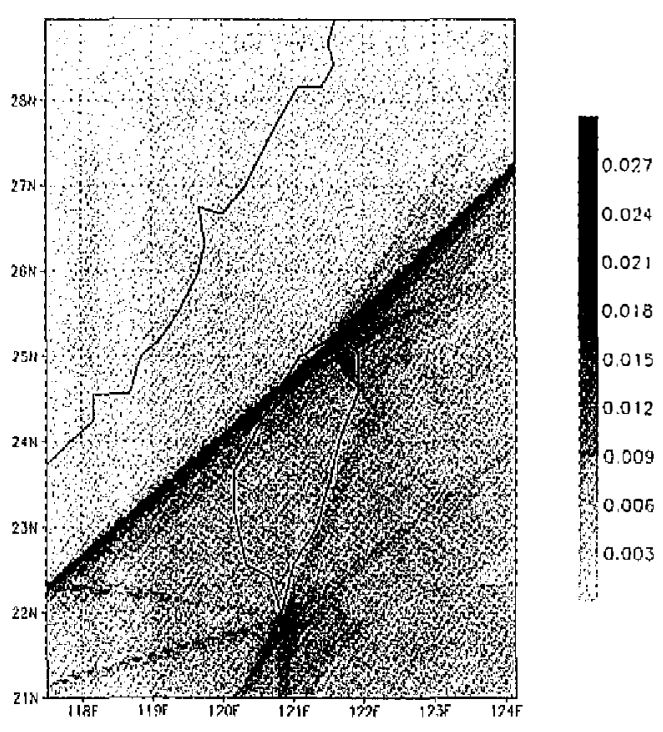

Fig. 11. Annual mean radiative forcing for the Taipei FIR. Values are calculated according to the radiative properties and occurrence probability of 12 contrail types and the flight frequency at different altitudes.

\subsection{A Day-by-day Evolution}

The above results indicate that contrail radiative forcing tends to have large spatial and temporal variations. In the following, a day-by-day estimation is performed to show how the radiative effects of contrails actually vary with time. We selected the same time period of 5/1 $\sim 5 / 10,1997$ used by Wang et al. (2001) in their regional model simulation so that comparisons can be made. Table 3 shows the contrail types at different altitudes for this time period according to the Ban-Chiao sounding and the criteria given in Table 1. In order to show the diurnal variations, we used the morning (08:00 local time) and evening (20:00 local time) soundings to represent daytime and nighttime situations, respectively. Contrail-forming atmospheric conditions exist at the $12-\mathrm{km}$ level (which carries $4 \%$ of the flights) for the whole 10 -day period, but exist only during the night of $5 / 1$ and on $5 / 2$ at the $11-\mathrm{km}$ level (which carries $63 \%$ of the flights). All other altitudes are not suitable for contrail development. Persistent contrails appear only during the daytime of 5/6 5/8 at the $12-\mathrm{km}$ level. Figure 12 shows the radiative forcing over the Taipei FIR at 12-hour intervals (note: the difference in day/night flight frequencies has been considered). The strongest radiative forcing $\left(0.1 \mathrm{~W} \mathrm{~m}^{-2}\right.$ in the longwave and $-0.27 \mathrm{~W} \mathrm{~m}^{-2}$ in the shortwave) occurs on $5 / 2$, mostly caused by the dissipating contrails at the 11-km level. Compared with the 3 days $(5 / 6 \sim 5 / 8)$ with persistent contrails formation, one can see that the factor of flight frequency outweighs the optical properties of contrails in this day-by-day case.

Besides significant day-to-day variations, one may also notice diumal variations in both the longwave and shortwave radiative forcing. The diurnal variations in the shortwave forcing are obviously a result of darkness during the night. The diurnal variation in the longwave forcing evidently is a result of changing contrail types according to Table 3 . It is interesting that the atmospheric conditions (hence the contrail types) at the 12-km level seem to have large diurnal oscillations (particularly in RHI), a topic that might be worthy of further studies. 
Table 3. Contrail types during 5/1 5/10, 1997 at different altitudes (in $1 \mathrm{~km}$ interval). Symbols $\mathrm{D}$ and $\mathrm{N}$ represent daytime and nighttime; and the numbers correspond to the contrail type shown in Table 1.

\begin{tabular}{|c|c|c|c|c|c|c|c|c|c|c|c|c|c|c|c|c|c|c|c|c|c|}
\hline \multirow{2}{*}{\multicolumn{2}{|c|}{$\frac{\text { Date }}{\text { Day/Night }}$}} & \multicolumn{2}{|c|}{$5 / 1$} & \multicolumn{2}{|c|}{$5 / 2$} & \multicolumn{2}{|c|}{$5 / 3$} & \multicolumn{2}{|c|}{$5 / 4$} & \multicolumn{2}{|c|}{$5 / 5$} & \multicolumn{2}{|c|}{$5 / 6$} & \multicolumn{2}{|c|}{$5 / 7$} & \multicolumn{2}{|c|}{$5 / 8$} & \multicolumn{2}{|c|}{$5 / 9$} & \multicolumn{2}{|c|}{$5 / 10$} \\
\hline & & D & $\mathrm{N}$ & D & $\mathrm{N}$ & D & $\mathrm{N}$ & D & $\mathbf{N}$ & D & $\mathrm{N}$ & D & $\mathrm{N}$ & D & $\mathrm{N}$ & D & 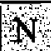 & D & $\mathrm{N}$ & D & 1 \\
\hline \multirow{2}{*}{ Type } & $12 \mathrm{~km}$ & 9 & 6 & 9 & 3 & 6 & 3 & 6 & 2 & 5 & 9 & 11 & 8 & 11 & 8 & 11 & 5 & 8 & 8 & 5 & 8 \\
\hline & $11 \mathrm{~km}$ & & 4 & 7 & 2 & & & & & & & & & & & & & & & & \\
\hline
\end{tabular}

The net radiative forcing to the surface is a cooling during the daytime and warming during the nighttime, thus causing a moderation of local climate. The daily (mean of the daytime and nighttime values) net radiative effects are negative for all but the first day, during which additional contrail formation occurs during the night at the $11-\mathrm{km}$ level. The mean radiative forcing over the Taipei FIR during these 10 days is only $-0.012 \mathrm{~W} \mathrm{~m}^{-2}$. However, a much higher local maximum of $0.7 \mathrm{~W} \mathrm{~m}^{-2}$ (longwave) and $-0.9 \mathrm{~W} \mathrm{~m}^{-2}$ (shortwave) occur at about $15 \mathrm{~km}$ east of the northern way-point APU (just above the Taipei City; see Lin et al. 2001).

\section{DISCUSSION AND CONCLUSION}

In this study we estimated the radiative effect of contrails over the Taiwan area with a combination of climatological analysis and numerical simulation of various contrail properties.

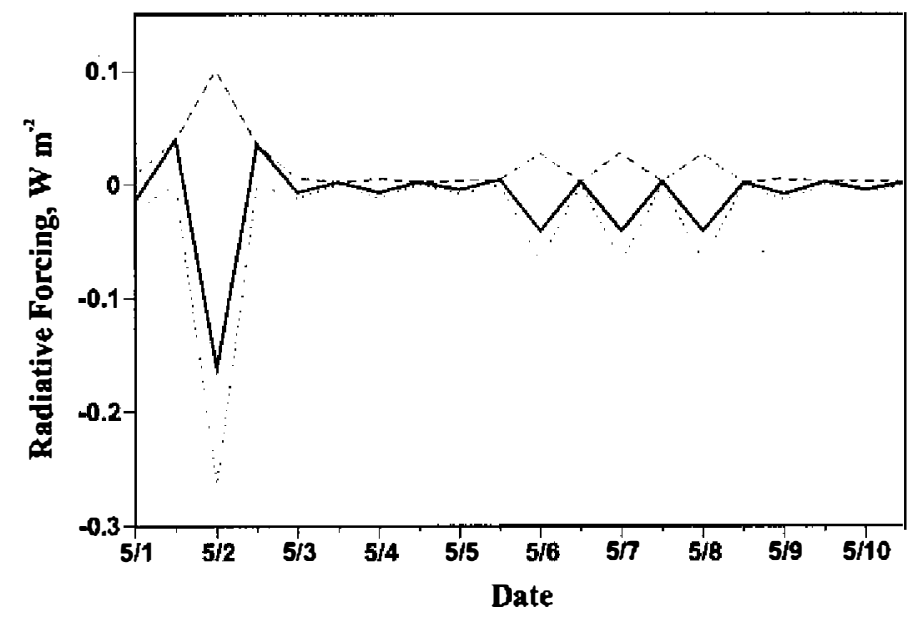

Fig. 12. Estimation of radiative forcing by contrails for the period of $5 / 1 \sim 5 / 10$, 1997. Note that in this figure the shortwave forcing (dotted line) is now plotted with the same flux direction as the longwave forcing (dashed line) for comparison, and is thus always negative. The net forcing (solid line) is always positive during the night and negative during the day. 
The most suitable altitudes for contrail formation are $14 \sim 16 \mathrm{~km}$. However, due to the flight altitude constraints, contrails are most likely to appear at heights between 10 and $12 \mathrm{~km}$. Winter and spring are the most favorable seasons for contrail formation, whereas summer is the least favorable. About $86 \%$ of the contrails will dissipate after formation (thus called dissipating contrails), while the rest may grow and persist for quite a long while (thus called persistent contrails).

In order to obtain detailed estimation of contrail radiative effects, we classified contrails into 12 types according to the atmospheric condition climatology. The evolution of each type of contrails was then simulated using a two-dimensional cirrus model with detailed dynamic, microphysical and radiative processes. From these simulations we obtained the time evolution of longwave and shortwave radiative forcing caused by each type of contrails. The timeaveraged longwave radiative forcing was about $1.1 \mathrm{~W} \mathrm{~m}^{-2}$ and $16 \mathrm{~W} \mathrm{~m}^{-2}$ directly under a dissipating and persistent contrail, respectively. For shortwave radiative forcing with the sun directly overhead, the values were $2.6 \mathrm{~W} \mathrm{~m}^{-2}$ and $40 \mathrm{~W} \mathrm{~m}^{-2}$, respectively.

In a spatial distribution the effects were much weaker because of the dilution effect by wind advection. Taking the upper-wind speed climatology into account, the time evolution of radiative effects were converted into spatial distributions. The spatial distributions are then mapped onto each flight corridor to obtain a regional distribution over the Taiwan area. On any particular day, the average longwave radiative forcing on a regional scale was about 0.08 $\mathrm{W} \mathrm{m}^{-2}$ if the atmospheric condition was suitable for dissipating-contrail formation, and was about $0.68 \mathrm{~W} \mathrm{~m}^{-2}$ for persistent contrails. The values for shortwave forcing were about 2.4 times greater, meaning the net effect was always a cooling of the surface temperatures. On an annual basis, the net regional effect was a rather weak cooling of $-0.006 \mathrm{~W} \mathrm{~m}^{-2}$ over the entire region, but may reach about $-0.03 \mathrm{~W} \mathrm{~m}^{-2}$ locally. These regional and local values were similar in magnitude (but opposite in sign) to those obtained by Minnis et al. (1999).

In the above results several interesting issues are worthy of further discussions. First, our results indicate that, unless most of the contrails occur during the night, the net effect of contrail formation should always be a cooling of the surface. Yet, the results of Fortuin et al. (1995) seem to suggest stronger warming effects than cooling. The one-dimensional modeling result of Liou and Gebhart (1982), the statistical analysis of Liou et al. (1990), and the regional and global estimations by Minnis et al. (1999) all indicate a net warming effect by the contrails. One the other hand, Kuhn (1970) observed a net decrease in radiative flux directly under the contrails. He estimated that if the contrails were persistent over a 24-hour period then the net effect would be a $5^{\circ}$ to $6^{\circ} \mathrm{C}$ cooling of surface temperatures. Whether contrails contribute to a warming or cooling to the surface temperatures actually depends on the latitude, length of day, and cloud emissivity (Kuhn 1970; Cox 1971). The discrepancies might result from atmospheric conditions or contrail optical properties that have significant geographical variations. In addition, most of the model calculation mentioned above applied a plain-parallel assumption for shortwave radiation, which might not be appropriate for width-limited contrails. In our calculation a more realistic Monte Carlo method was applied.

Another important factor is the ratio of daytime versus nighttime flight frequencies. As discussed in the previous section, more flights in the daytime (nighttime) means more con rail occurrence and stronger cooling (warming) effects. Mannstein et al. (1999) showed that con- 
trail coverage in Europe at nighttime is one-third that in the daytime. This ratio is somewhat lower than the proportion of $34 \%$ nighttime flights versus $66 \%$ daytime flights used in this study (from Lin et al. 2001). The discrepancy might result either from different flight operations or different contrail development during the daytime versus nighttime. In any case, the diurnal variation in flight frequency has significant impact on not only the magnitude but also the sign of net radiative forcing.

The relative roles of dissipating and persistent contrails also need to be clarified. Ponater et al. (1996) indicated that short-lived dissipating contrails have much smaller spatial and temporal scales, hence contribute much less to the radiation budgets. IPCC (1999) also suggested that contrails are radiatively important only when they are persistent and spread to several-kilometer lateral widths and a few hundred meters depth. However, at least for the Taipei FIR region, the frequency of dissipating contrails far exceeded that of persistent contrails (by almost 20 times; see Table 1 ). As a consequence, about $2 / 3$ of the annual regional radiative forcing shown in Fig. 11 are contributed by dissipating contrails even though their individual effect is much weaker. If the dominance of dissipating contrails we obtained is a global phenomenon, then the results of many regional and global studies that consider only persistent contrails may require significant adjustment.

The global or regional radiative effects of contrails shown by this and various other studies are rather weak compared with the estimated anthropogenic greenhouse effect, so one is safe to say that current radiative forcing by contrails is insignificant on a global scale. However, the effect can be quite strong locally, at least over some short period of times. We should also keep in mind the rapid increase in aircraft activities, particularly in the Asian Pacific region. IPCC (1999) estimated that, with a 3-fold increase in aircraft fuel, a 5-fold increase in contrail cover and 6-fold increase in radiative forcing are expected. Furthermore, the occurrence of contrails does not increase linearly with the growth of aircraft activities. Flying altitudes may expand upward if the airspace becomes too crowded or new aircraft design allows higher altitudes. For instance, since the 1960 's, the cruise altitudes of propeller driven aircraft have risen from about 3 to about $7.5 \mathrm{~km}$. The emergence of jet- and turbofan-powered aircraft pushed the flying altitudes up at 10.5 to $11.5 \mathrm{~km}$ (IPCC 1999). As shown in Fig. 4, the probability of contrail formation increases upward rather rapidly above the typical cruising altitudes currently in use. More contrails will form as a result of higher flying altitude. The same concern also applies to the future supersonic fleet flying above the 16-km altitude. One should also note that the air temperature at the cruising altitudes generally decreases with increasing latitude, thus contrails are more likely to form in flight corridors over higher latitudes.

Finally, we must admit that there are numerous uncertainties and potential errors in our estimation. For instance the occurrence frequency of contrails in Fig. 5 lacks observational validation. Photographic evidence should be gathered and analyzed in the future. Also, using a single sounding station (even though it is a five-year climatology) to represent the entire Taipei FIR neglects the spatial distribution of meteorological parameters. More serious discrepancies might result from the model-generated contrail properties, which were simulated under simplified conditions. One of the critical simplifications is a specified initial ice particle number concentration in the contrail. The actual number concentration not only depends on particle nucleation in the combustion exhausts but also on the cooling rate and available water 
vapor in the atmosphere. In addition, our simulations did not consider vertical wind shear in the cross-contrail direction. Such wind shear may cause a lateral spreading and enhanced growth of contrails as shown by Jensen et al. (1998) in their model simulations. Sassen (1997) indicated that $28 \%$ of the contrails observed have extensive spreading. In this case, our simulations may significantly underestimate the contrail coverage. In the estimation of radiative forcing on surface temperatures, we did not consider the overlap of low level clouds, which may at least partially cancel the effects. In spite of all the uncertainties, this study provides a first estimation of contrail effects over the Taiwan area with a first-order accuracy.

Acknowledgments This research was supported by the National Science Council under Grants NSC-87-2621-P-002-002, NSC-87-2811-M-002-0019 and NSC-88-2111-M-002-016.

\section{REFERENCES}

AEROCHEM, 1997: Modeling of the Impact on Ozone and other Chemical Compounds in the Atmosphere from Aeroplane Emissions. Proposal submitted to the Commission of the European Community -DG XII, 48 pp.

ATAG, 1997: Asia/Pacific Air Traffic Growth and Constraints. Air Transport Action Group, Geneva, Switzerland, $50 \mathrm{pp}$.

Bakan, S., M. Betancor, V. Gayler, and H. Grassl, 1994: Contrail frequency over Europe from NOAA-satellite images. Annales Geophysicae, 12, 962-968.

Betancor Gothe, M., and H. Grassl, 1993: Satellite remote sensing of the optical depth and mean crystal size of thin cirrus and contrails. Theor. Appl. Clim., 48, 101-113.

Boucher, O., 1998: Is the Observed Trend in Cirrus Occurrence Due to Aviation? Note Interne du LOA No. 1, Laboratoire d'Optique Atmospherique, UFR de Physique, Universite de Lille-I, Villeneuve d'Ascq, France, 17 pp.

Boucher, O., 1999: Influence of air traffic on cirrus occurrence. Nature, 397, 30-31.

Changnon, S. A., 1981: Midwestern sunshine and temperature trends since 1901: possible evidence of jet contrail effects. J. Appl. Meteor., 20, 496-508.

Chen, J.-P., and R.-F. Lin, 2001: Numerical simulation of contrail microphysical and radiative properties. $T A O, 12,137-154$.

Chlond, A., 1996: Large-eddy-simulation of contrails. Report No. 204, Max-Planck-Institut fur Meteorologie, $39 \mathrm{pp}$.

Cox, S. K., 1971: Cirrus clouds and climate. J. Atmos. Sci., 28, 1513-1515.

Fortuin, J. P., F., R. van Dorland, W.M.F. Wauben, and H. Kelder, 1995: Greenhouse effects of aircraft emissions as calculated by a radiative transfer model. Ann. Geophysicae, 13, 413-418.

Frankel, D., K.-N. Liou, S.C. Ou, D. P. Wylie, and P. Menzel, 1997: Observations of cirrus cloud extent and their impacts to climate. Proceedings, Ninth Conference on Atmospheric Radiation, February 2-7, 1997, Long Beach , CA, Amer. Meteor. Soc., 414417.

Gayet, J.-F., G. Febvre, G. Brogniez, H. Chepfer, W. Renger, and R. Wendling, 1996: Microphysical and optical properties of cirrus contrails: Cloud field study on 12 October 
1989. J. Atmos. Sci., 53, 126-138.

Gierens, K., R. Sausen, and U. Schumann, 1999: A diagnostic study of the global distribution of contrails. Part II: Future air traffic scenarios. Theor. Appl. Climatol., 63, 1-9.

Grassl, H., 1991: Possible climatic effects of contrails and additional water vapor. Air Traffic and the Environment - Background, Tendencies and Potential Global Atmospheric Effects. In: U. Schumann (Ed.), Springer-Verlag, 124-137.

IPCC, 1999: Aviation and the Global Atmosphere. Editors: J. E. Penner, D. H. Lister, D. J. Griggs, D. J. Dokken, and M. Mcfarland, Intergovernmental Panel on Climate Change, Cambridge University Press, 373 pp.

Jensen, E. J., A. S. Ackerman, D. E. Stevens, O. B. Toon, and P. Minnis, 1998: Spreading and growth of contrails in a sheared environment. J. Geophys. Res., 103, 31557-31567.

Kuhn, P. M., 1970: Airborne observations of contrail effects on the thermal radiation budget. J. Atmos. Sci., 27, 937-942.

Liepert, B., P. Fabian, and H. Grassl, 1994: Solar radiation in Germany - observed trends and an assessment of their causes. Part I: regional approach. Beitrage zur Physik der Atmosphare, 67, 15-29.

Liepert, B., 1997: Recent changes in solar radiation under cloudy conditions. Int. J. Climatology, 17, 1581-1593.

Lin, W.-H., 2000: Contrail physical characteristics over the Taipei Flight Information Region. Master Thesis, National Taiwan University, 79 pp. (in Chinese)

Lin, P.-H., W.-S. Sun, and J.-P. Chen, 2001: The inventory of civil aircraft emissions over Taiwan. TAO, 12, 39-60.

Liou, K. N., 1986: Influence of cirrus clouds on weather and climate processes: A global perspective. Mon. Wea. Rev., 114, 1167-1199.

Liou, K. N., and K. L. Gebhart, 1982: Numerical experiments on the thermal equilibrium temperature in cirrus cloudy atmospheres. J. Meteor. Soc. Japan, 60, 570-582.

Liou, K.-N., S. C. Ou, and G. Koenig, 1990: An investigation of the climatic effect of contrail cirrus. Air Traffic and the Environment: Background, Tendencies, and Potential Global Atmospheric Effects. In U. Schumann (Ed.), Springer-Verlag, Berlin, Germany, 154-169.

Mannstein, H., R. Meyer, and P. Wendling, 1999: Operational detection of contrails from NOAA-AVHRR data. Intl. J. Remote Sensing, 20,1641-1660.

Minnis, P., J. K. Ayers, and S. P. Weaver, 1997: Surface-based observations of contrail occurrence frequency over the U. S., April 1993-April 1994. NASA Reference Publication 1404, National Aeronautics and Space Administration, Hampton, V. A., USA, 79 $\mathrm{pp}$.

Minnis, P., D. F. Young, D. P. Garber, L. Nguyen, W. L., Smith, Jr., and R. Palikonda, 1998: Transformation of contrails into cirrus during SUCCESS. Geophys. Res. Lett., 25, 11571160.

Minnis, P., U. Schumann, D. R. Doelhing, K. M. Gierens, and D. W. Fahey, 1999: Global distribution of contrail radiative forcing. Geophys. Res. Lett., 26, 1853-1856.

Minnis, P., U. Schumann, D. R. Doelhing, J. K. Ayers, R. Palikonda, L. Nguyen, D. F. Young, and K. M. Gierens, 2000: Contrails: another factor in climate change? To be appeared 
in Science.

Murcray, W. B., 1970: On the possibility of weather modification by aircraft contrails. Mon. Wea. Rev., 98, 745-748.

Ponater, M., S. Brinkop, R. Sausen, and U. Schumann, 1996: Simulating the global atmospheric response to aircraft water vapor emissions and contrails: a first approach using a GCM. Annales Geophysicae, 14, 941-960.

Pratt, R. W., 1985: Review of radiosonde humidity and temperature errors. J. Atmos. Oceanic Tech, 2, 404-407.

Rebetez, M., and M. Beniston, 1998: Changes in sunshine duration are correlated with changes in daily temperature range this century: An analysis of Swiss climatology data. Geophys. Res. Lett., 25, 3611-3613.

Sassen, K., 1997: Contrail-cirrus and their potential for regional climate change. Bull. Amer. Meteor. Soc., 78, 1885-1903.

Sausen, R., K. Gierens, M. Ponater, and U. Schumann, 1998: A diagnostic study of the global distribution of contrails, Part I: Present day climate. Theor. Appl. Clim., 61, 127-141.

Schumann, U., 1994: On the effect of emissions from aircraft engines on the state of the atmosphere. Ann. Geophys., 12, 365-384.

Schumann, U., 1996: On conditions for contrail formation from aircraft exhausts. Meteorol. Zeitschrift, 5, 4-23.

Seaver, W. L., and J. E. Lee, 1987: A statistical examination of sky cover changes in the contiguous United States. J. Climate Appl. Meteor., 26, 88-95.

Strauss, B. R. Meerkotter, B. Wissinger, P. Wendling, and M. Hess, 1997: On the regional climatic impact of contrails: microphysical and radiative properties of contrails and natural cirrus clouds. Annales Geophysicae, 15, 1457-1467.

Vandersee, W., 1997: Strahlungsme $\beta$ reihe am MOHp. Promet, 26 (1/2), 8-16.

Winkler, P., L. Gantner, and U. Köhler, 1997: Hat sich wegen der langfristigen Ozonabnahme die UV-Strahlung erhöht? In: Deutscher Wetterdienst, Offenbach and Main, Germany, Vol. 49, 37 pp.

Wang, W.-C, W. Gong, and J.-P. Chen, 2001: SUNYA regional model simulation of radiative forcing and climate responses due to contrails over regions around Taiwan. TAO, 12, 179-194. 